\title{
Antioxidant properties of green tea polyphenols encapsulated in caseinate beads
}

\author{
Masood Dehkharghanian ${ }^{1}$, Stéphane SalmierI ${ }^{2}$, Monique Lacroix ${ }^{2 *}$, \\ Mookambeswaran A. VIJAYALAKSHMI ${ }^{1}$ \\ ${ }^{1}$ Laboratoire d'Interactions Moléculaires et des Technologies de Séparation (LIMTech.S), \\ Centre de recherche de Royallieu, Université de Technologies de Compiègne, B.P. 20.529, \\ 60205 Compiègne Cedex, France \\ ${ }^{2}$ INRS-Institut ARMAND-FRAPPIER, Research Laboratories in Sciences Applied to Food, \\ 531 boulevard des Prairies, Laval, Québec, H7V 1B7, Canada
}

Received 12 August 2009

Published online 19 September 2009 - (C) INRA, EDP Sciences, 2009

Dairy Sci. Technol. 89 (2009) 485-499

An error occurred in the list of authors of the article: Dehkharghanian M., Lacroix M. and Vijayalakshmi M.A., Antioxidant properties of green tea polyphenols encapsulated in caseinate beads, Dairy Sci. Technol. 89 (2009) 485-499. Therefore the correct reference of the article is:

Dehkharghanian M., Salmieri S., Lacroix M. and Vijayalakshmi M.A., Antioxidant properties of green tea polyphenols encapsulated in caseinate beads, Dairy Sci. Technol. 89 (2009) 485-499.

*Corresponding author: Monique.lacroix@iaf.inrs.ca 